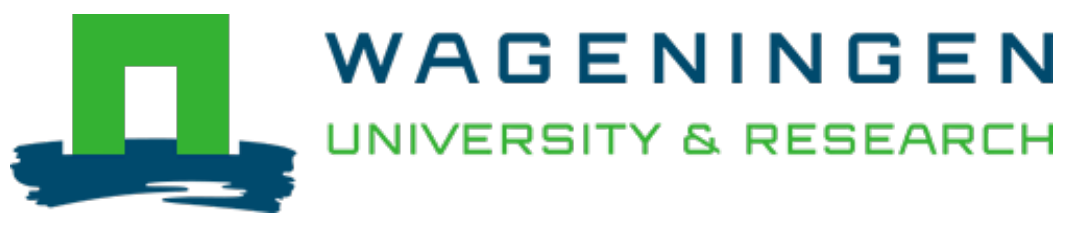

\title{
A desertification risk assessment decision support tool (DRAST)
}

Catena

Karavitis, Christos A.; Tsesmelis, Demetrios E.; Oikonomou, Panagiotis D.; Kairis, Orestis; Kosmas, Constantinos et al

https://doi.org/10.1016/j.catena.2019.104413

This publication is made publicly available in the institutional repository of Wageningen University and Research, under the terms of article $25 \mathrm{fa}$ of the Dutch Copyright Act, also known as the Amendment Taverne. This has been done with explicit consent by the author.

Article $25 \mathrm{fa}$ states that the author of a short scientific work funded either wholly or partially by Dutch public funds is entitled to make that work publicly available for no consideration following a reasonable period of time after the work was first published, provided that clear reference is made to the source of the first publication of the work.

This publication is distributed under The Association of Universities in the Netherlands (VSNU) 'Article $25 \mathrm{fa}$ implementation' project. In this project research outputs of researchers employed by Dutch Universities that comply with the legal requirements of Article $25 \mathrm{fa}$ of the Dutch Copyright Act are distributed online and free of cost or other barriers in institutional repositories. Research outputs are distributed six months after their first online publication in the original published version and with proper attribution to the source of the original publication.

You are permitted to download and use the publication for personal purposes. All rights remain with the author(s) and / or copyright owner(s) of this work. Any use of the publication or parts of it other than authorised under article $25 \mathrm{fa}$ of the Dutch Copyright act is prohibited. Wageningen University \& Research and the author(s) of this publication shall not be held responsible or liable for any damages resulting from your (re)use of this publication.

For questions regarding the public availability of this publication please contact openscience.library@wur.nl 


\title{
A desertification risk assessment decision support tool (DRAST)
}

\author{
Christos A. Karavitis ${ }^{a, *}$, Demetrios E. Tsesmelis ${ }^{\mathrm{a}}$, Panagiotis D. Oikonomou ${ }^{\mathrm{b}}$, Orestis Kairis ${ }^{\mathrm{a}}$, \\ Constantinos Kosmas a, Vassilia Fassouli ${ }^{\mathrm{a}}$, Coen Ritsema ${ }^{\mathrm{c}}$, Rudi Hessel ${ }^{\mathrm{d}}$, Victor Jetten ${ }^{\mathrm{e}}$, \\ Nikolaos Moustakas ${ }^{\mathrm{a}}$, Branislav Todorovic ${ }^{\mathrm{a}}$, Nikolaos A. Skondras ${ }^{\mathrm{a}}$, Constantina G. Vasilakou ${ }^{\mathrm{a}}$, \\ Stavros Alexandris ${ }^{\mathrm{a}}$, Elpida Kolokytha ${ }^{\mathrm{f}}$, Demetrios V. Stamatakos ${ }^{\mathrm{a}}$, Ruzica Stricevic ${ }^{g}$, \\ Emmanuel Chatzigeorgiadis ${ }^{\mathrm{h}}$, Jane Brandt ${ }^{\mathrm{i}}$, Nicky Geeson ${ }^{\mathrm{i}}$, Giovanni Quaranta ${ }^{\mathrm{i}}$ \\ ${ }^{\text {a }}$ Department of Natural Resources Development \& Agricultural Engineering, Agricultural University of Athens, 11855 Athens, Greece \\ ${ }^{\mathrm{b}}$ Colorado Water Institute, Colorado State University, Campus Delivery 1033, Fort Collins, CO 80523-1033, USA \\ ${ }^{\mathrm{c}}$ Soil Physics and Land Management Group, Wageningen University \& Research, Droevendaalsesteeg 4, 6708 PB Wageningen, the Netherlands \\ ${ }^{\mathrm{d}}$ Soil Physics and Land Use, Alterra, Wageningen University \& Research, P.O. Box 47, 6700 AA Wageningen, the Netherlands \\ ${ }^{\mathrm{e}}$ Faculty of Geo-Information Science and Earth Observation (ITC), University of Twente, PO Box 217, 7500 AE Enschede, the Netherlands \\ ${ }^{\mathrm{f}}$ Division of Hydraulics and Environmental Engineering, Department of Civil Engineering, Aristotle University of Thessaloniki, University Campus, 54124 Thessaloniki, \\ Greece \\ ${ }^{\mathrm{g}}$ Faculty of Agriculture, University of Belgrade, Nemanjina 6, 11080 Zemun, Serbia \\ ${ }^{\mathrm{h}}$ Agricultural University of Athens, 11855 Athens, Greece \\ ${ }^{\mathrm{i}}$ Osservatorio Mediterraneo per lo Studio delle Soluzioni dei Problemi Economici della aree a Rischio Desertificazione (MEDES), Via Fossa del Lupo n.1, Sicignano degli \\ Alburni, 84029 Salerno, Italy
}

\section{A R T I C L E I N F O}

\section{Keywords:}

Desertification risk

Desertification assessment

Desertification indicators

Decision support systems

Expert systems

Web-based systems

Land and water resources management

Strategies to combat desertification

\begin{abstract}
A B S T R A C T
Desertification constantly and diachronically manifested itself as one of the most critical environmental issues to be confronted and mitigated by society. This work presents the development of a land desertification risk Expert System (ES) for assessing the application of different land management practices by utilizing indicators through a desertification risk index (DRI). The DRI was developed by a desertification risk assessment framework generated in seventeen study sites worldwide. This assessment was performed through a methodological process incorporating indicators suited to a plethora of physical, social and economic characteristics. Then, the Desertification Risk Assessment Support Tool (DRAST) was created using the indicators' methodology in an effort to efficiently handle complexity and variability in soil and water resources management. To demonstrate DRAST's applicability, an independent data base of indicators was used, and the tool was employed in all the seventeen study sites. Five indicative sites, experiencing different desertification processes, are selected as key representatives of the methodological process implementation. Overall, the assessment depicted that DRAST performs appropriately in demarcating existing desertification risk as well as in portraying how the desertification risk changes after the application of pertinent mitigation actions. Thus, the current approach may lead towards a standardized procedure, which is using the advantages of information technology to assess the effectiveness of various land management practices and facilitate stakeholders and decision-makers to produce and implement timely and appropriate responses to combat desertification.
\end{abstract}

\section{Introduction}

Within the last few decades, the geopolitical nature of land use rests on a combination of geography and technology. Across the world, there are different historical and cultural traits influencing ecological adaptations and capabilities, as well as exhibiting various degrees of power and command over natural resources. The degradation of national, regional, and local land resources, advancing desertification, and expanding socio-economic demands have fueled confrontations and they have also forced international exchanges and cooperation. As a result, desertification constantly and diachronically manifested itself as one of the most critical environmental issues to be confronted and mitigated by society (Briassoulis, 2019; Thomas, 1997; UNEP, 1992). Efficient land desertification mitigation measures require appropriate land

\footnotetext{
* Corresponding author.

E-mail address: ckaravitis@aua.gr (C.A. Karavitis).
} 
management practices accompanied by policy that promotes sustainability and improves ecosystem services. For any desertification-affected areas, cumulative efforts and pertinent research indicate that it is essential to focus on protection, prevention, and anticipatory planning efforts rather than on post hoc restoration and/or rehabilitation options. Each time these options are applied and since these areas are usually at a high stage of deterioration, the expected results may be ambiguous or minimally effective (Hessel et al., 2014; Kairis et al., 2014; Kosmas et al., 2003, 2014; Salvati et al., 2015, 2016; Tsesmelis et al., 2019a).

Furthermore, desertification is a continuously controversial issue both temporally and spatially, with complex interrelations between the societal impacts and the natural environment (Peters et al., 2015; Vlachos, 1982). Such a controversial issue is principally arisen by the absence of a universally accepted methodological framework of "what to measure" and "how to measure it". This framework should simultaneously operate in a complex system full of interrelations. One of the main avenues to represent such interrelations and communicate them with policymakers is through indicators. Indicators assist with monitoring the implementation of systemic policy objectives, and they represent trends and developments in the state of a system. Numerous and diverse system interrelations may be reflected in the corresponding number and diversity of the indicators used. Furthermore, whenever new sets of interrelations are analyzed they usually need to be represented by new sets of indicators. Overall, indicators are growing to be increasingly valuable means for conveying information about the state of the environment to the decision makers and the lay public (Karavitis et al., 2014; Kibblewhite et al., 2007; Kosmas et al., 2003; Oikonomou, 2017; Tsesmelis et al., 2019b). They can be used to assess environmental performance and to evaluate the changes made by anthropogenic actions and/or physical processes. Thus, they constitute as a useful tool in land management efforts (Kairis et al., 2014; Kosmas et al., 2014; Tsesmelis, 2017). However, particularly in environmental sciences, a sole indicator may not effectively portray a complex process such as soil erosion, which is a key driver of land desertification. Indicators forming a composite index may allow the derivation of multiple options in land management. Hence, they may successfully monitor the existing or the resulting from pertinent interventions state of the environment (Basso et al., 2000; Karavitis et al., 2015, 2014; Kosmas et al., 2003, 1999; Oikonomou et al., 2019; Oikonomou and Waskom, 2018; Skondras et al., 2011; Tsesmelis et al., 2019a).

Desertification manifests when land and water resources are degraded beyond certain thresholds. Such degradation is leading to irreversible changes and to a new non-desirable state (Briassoulis, 2005; Kosmas et al., 1999). Desertification indicators may clearly illustrate that the phenomenon per se has already progressed to its endpoint creating an irreversibly unproductive land. Dating back to the 1970s, the desertification indicators usually were generated to evaluate desert advances. In the 1980s, the need for holistic and adaptable desertification combating approaches was greatly intensified. As a result, indicator frameworks were proposed. Initially, Rubio and Bochet (1998) presented a detailed desertification indicator framework and synthesized lists of criteria including a methodology for the selection, assessment, and application of pertinent indicators. A part of this arsenal was the significant attempt to produce an Environmentally Sensitive Areas Index (ESAI) made by the European Commission's (EC) "MEDALUS III" research project (Kosmas et al., 1999). In this effort, a set of dominant indicators depicting various desertification drivers (soil, climate, vegetation, management) synthesized a composite land desertification index. The ESAI methodology was extensively applied for more than a decade directly or indirectly (e.g. Salvati, 2012; Tsesmelis et al., 2019a). However, it was argued that it exhibited an absence of social and economic components related to parameters such as population growth rate, economic conditions, and population density (Salvati et al., 2016, 2007; Salvati and Bajocco, 2011).

Recatala et al. (2002) employed environmental indicators to evaluate and monitor desertification and its pressure in the Mediterranean region. In this regard, the stocking rate universal indicator was found to be an important one incorporating all the factors affecting the impacts of grazers on soil, land degradation, and desertification processes (Pulina et al (1998). Furthermore, Fierotti and Zanchi (1998) proposed as a global indicator the degree of soil erosion. However, this requires field observations for its rapid and easy assessment. They have also suggested that other specific indicators may contribute to the estimation of soil erosion such as the degree of vegetation cover, the vegetation productivity, the trend of various soil physical characteristics, the vegetation growth rate, the organic matter content and development, and the intensity of erosive forms. The EC ENVASSO project for three threats namely: decline of organic matter, soil erosion and soil salinization, chose the corresponding indicators as the most relevant ones to describe the land desertification in arid, semi-arid, and dry subhumid zones (Kibblewhite et al., 2007). One of the objectives of the DESIRE project was to investigate the use of indicators as a means to assess the processes of land degradation and desertification at a global scale (DESIRE, 2012). To achieve this, indicators were selected that proved to be more appropriate to assess the variety of land management practices to confront desertification. In addition to that, they should also be applicable on a broad spectrum of natural, environmental, social, and economic characteristics portrayed in the carefully chosen project's study sites as exemplified by Kosmas et al (2014). However, one should keep in mind that similar mechanisms or interrelated driving forces, mostly of anthropogenic nature, generally drive different desertification processes. Although the indicators to be used for each of such processes are different, this similarity in driving forces may allow for the development of a broad enough indicator approach that can be used to assess desertification (Kosmas et al., 2014).

Land users or land policymakers typically need straightforward tools to identify the current state of a socioeconomic and ecological system and to foresee trends and problems due to land desertification caused by such processes or causes. In this context, the information technology, in the form of Expert Systems (ES) and other related Decision Support Systems (DSS), may offer some ubiquitous advantages as a part of desertification mitigation strategies. Throughout the last decades, ES have been widely used by a variety of managers and researchers in a multidisciplinary context of decision making in different disciplines and natural regimes. The contribution of ES in natural resources and environmental management is of great significance and it advances more and more rapidly. Early on in the literature, Rykiel (1989) described the use of Artificial Intelligence and ES in ecology and natural resources management, while Mohan and Arumugam (1997) provided an overview of expert systems application in irrigation management. Karavitis (1999) reported an expert system developing since 1992 and applied for drought management in various locales, whereas Brandt and Geeson (2005) included a simple web-based ES for Desertification Risk estimation in the DIS4ME Desertification Information System. Witlox (2005) provided an overview of expert systems application in land use planning. López et al. (2008) presented expert systems in soil characterization, and furthermore, Genske and Heinrich (2009) described an ES for degraded terrain analysis. Thus, the development of a DSS in the form of a risk estimation ES should present an essential tool in desertification mitigation efforts. All in all, an ES used in Desertification Risk estimation should, above all, serve as a "common language" among the different groups involved in the decision-making process. It should serve as a communication "bridge" among managers, politicians, scientists, and administrators. At the same time, apart from being a communication tool, it should also provide an analysis of the various components of the problem. In addition, some special features should be included such as simplicity, interactive ability, and credibility.

In this quest, the advantages of computer technology for the development of an indicator based DSS are unambiguous. They include the possibility to: analyze a wide spectrum of alternative options for 
land management practices; assess and select the main indicators through which desertification risk may be categorized in various locales worldwide; and develop consensus among different groups (politicians, managers, experts, etc.) in assessing desertification risks. In this context, the DSS may allow stakeholders and decision-makers to arrive at timely, efficient, and appropriate desertification mitigation responses. It may also provide a standard to evaluate the effectiveness of various land management practices.

In this regard, relevant assessment methods have been derived for the different processes or causes of desertification by using an indicator approach, which tried to incorporate both physical and anthropogenic parameters. Previously, this methodological procedure was tested mostly within the Mediterranean Region (Benabderrahmane and Chenchouni, 2010; Brandt and Geeson, 2005; Kosmas et al., 2000a, 2000b, 1999; Parvari et al., 2011; Salvati et al., 2015, 2007). Hence, the DESIRE project application in a worldwide scale offered quite a challenge and it has led in innovative progress by assessing desertification risk according to a variety of physical characteristics, environmental impacts, social structure, as well as economic and land management conditions. This approach presented a composite desertification risk index based on all the above-mentioned parameters (Kairis et al., 2014; Kosmas et al., 2014). Overall, the novelty of the current effort is twofold. The first one was to develop an ES based on the derived algorithms from the pertinent novel desertification methodology stemming from the research of the DESIRE project. This novel ES should offer decision support to various stakeholders' groups, in an effort to assess land desertification risk under multiple physical, environmental, economic, and social conditions. In continuation, the second novel objective was to apply this ES using two different databases in the DESIRE Project diverse study sites worldwide. To this end, the next methodological step was to present, visualize, and assess the outcomes. Such assessment may prove the worldwide applicability of the ES and thus aid in decision making focused on delineating suitable land management practices and techniques to combat desertification on both a regional and a global scale.

\section{Methodology}

\subsection{Desertification risk estimation using indicators}

An integrated approach towards assessing the desertification stages through the incorporation of various indicators was applied within the framework of the DESIRE project (Hessel et al., 2014). Kosmas et al. (2014) reported an array of candidate indicators that was compiled by: (a) an extensive literature review, (b) stakeholders consultation such as groups of land users, managers, decision makers, and research groups on desertification and land degradation both locally or regionally in every study site, as well as internationally; and (c) applying existing research already performed in projects on land degradation and desertification (Medalus, 1996; Kosmas et al., 1999; Enne and Zucca, 2000; Wascher, 2000; DESERTLINKS, 2004; OECD, 2004; MEDRAP, 2004; Liniger et al., 2007). Details about the literature review, the pertinent research, and the stakeholders participation processes are available in the DESIRE-HIS (DESIRE, 2012). Kosmas et al. (2014) produced an indicator list that was combining robust indicators, as aridity index, with indicators that the stakeholders felt that they were relevant as soil depth, water quality, etc. A detailed presentation of all the indicators employed in this effort is also available on the DESIRE project deliverables and website (DESIRE, 2012).

In summarizing, according to Kosmas et al. (2014) and Kairis et al. (2014), the principal processes-drivers or causes of land desertification were: soil erosion including water and tillage erosion, soil salinization, water stress, forest fires, and overgrazing, as found in the DESIRE study sites in the Mediterranean and Eastern Europe, Latin America, Africa, and Asia. It should be noted that aeolian erosion was encountered in only one study site, the Karapınar Plain, Konya, Turkey (Fig. 3). In addition to the limiting factor of obtain data from only one area, these existing in situ data were very sparse, non-dependable, and fragmented. Thus, they could not be used in the indicators derivation process (DESIRE, 2012). It is suggested that in a future research effort, pertinent study sites including a significant number of aeolian erosion suffering

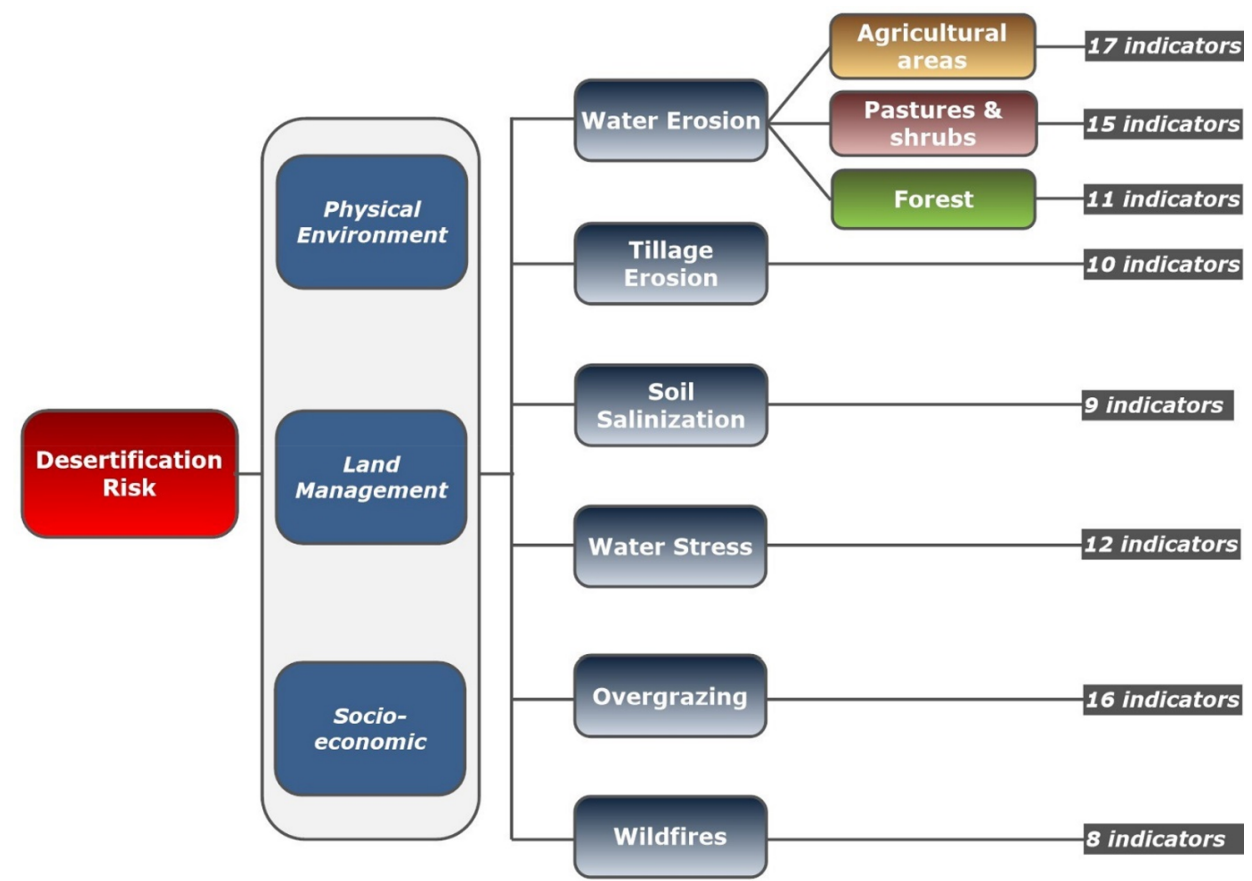

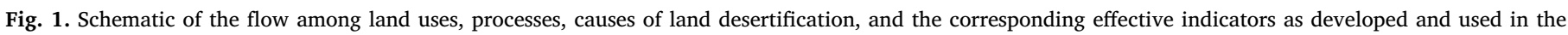
decision support tool. 


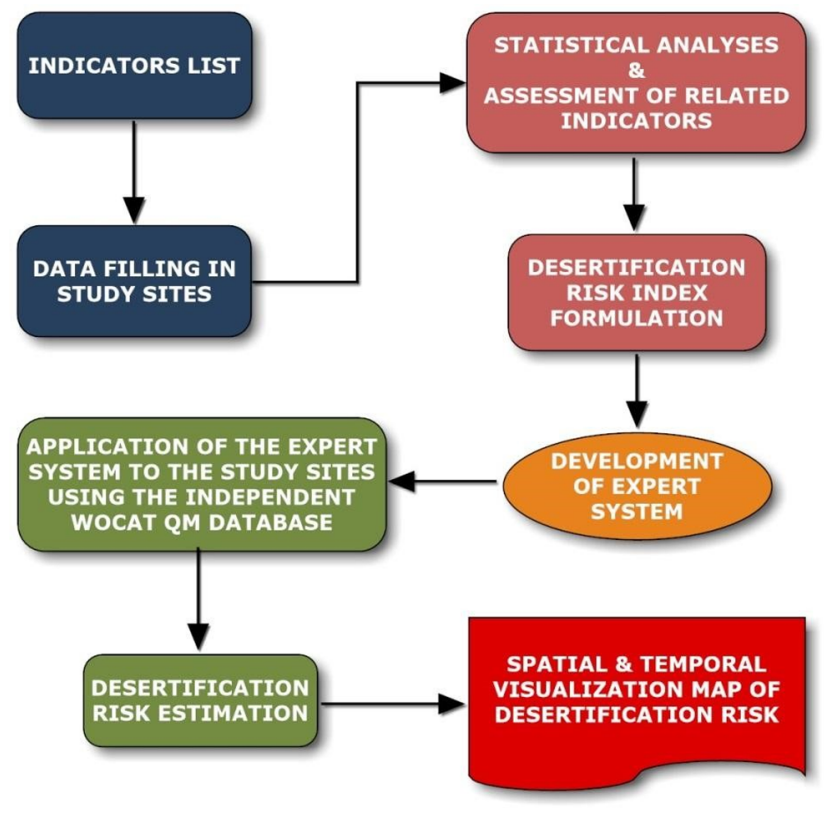

Fig. 2. The methodological framework for desertification risk estimation and Expert System (ES) development. areas should be incorporated, so that the indicator methodology could be applicable, and then the results to be imbedded in a revised ES. Thus, in the current effort, the candidate indicators were categorized among the various processes-drivers or causes of land desertification apart from aeolian erosion and then analyzed. Kosmas et al. (2014) described in detail such an analysis. Briefly, for every indicator, its range of potential values was categorized into four or five classes. The indicators values were computed in an annual time step (e.g. potential evapotranspiration, rainfall, water scarcity, etc.) or from a series of in situ measurements (e.g. soil parent material, slope gradient, soil depth, etc.) through the course of the DESIRE project (Kairis et al., 2014; Kosmas et al., 2014). All the values, their time, and space resolution are presented in detail in the DESIRE deliverables (DESIRE, 2012). The first step for this categorization was the use of existing classification systems such as the European geo-referenced soil database (Finke et al., 1998; Kosmas et al., 1999; Liniger et al., 2007; van Engelen and Wen, 1995; van Engelen et al., 2005). The second step was to utilize existing pertinent research data (Brandt and Geeson, 2005; Kosmas et al., 2000a, 2000b, 1999). For reference comparison purposes among the various regions, a common weighting system was applied. Hence, five classes of desertification risk demarcated as none, low, moderate, high, and very high. Coefficients were assigned for every class of desertification risk ranging from 1 (none) to 5 (very high) and explicitly presented by Kosmas et al. (2014) and Kairis et al. (2014). Based on these, a similar classification scheme was followed for the visualization of the desertification risk in the ES (Fig. 4). Since various case studies exhibited
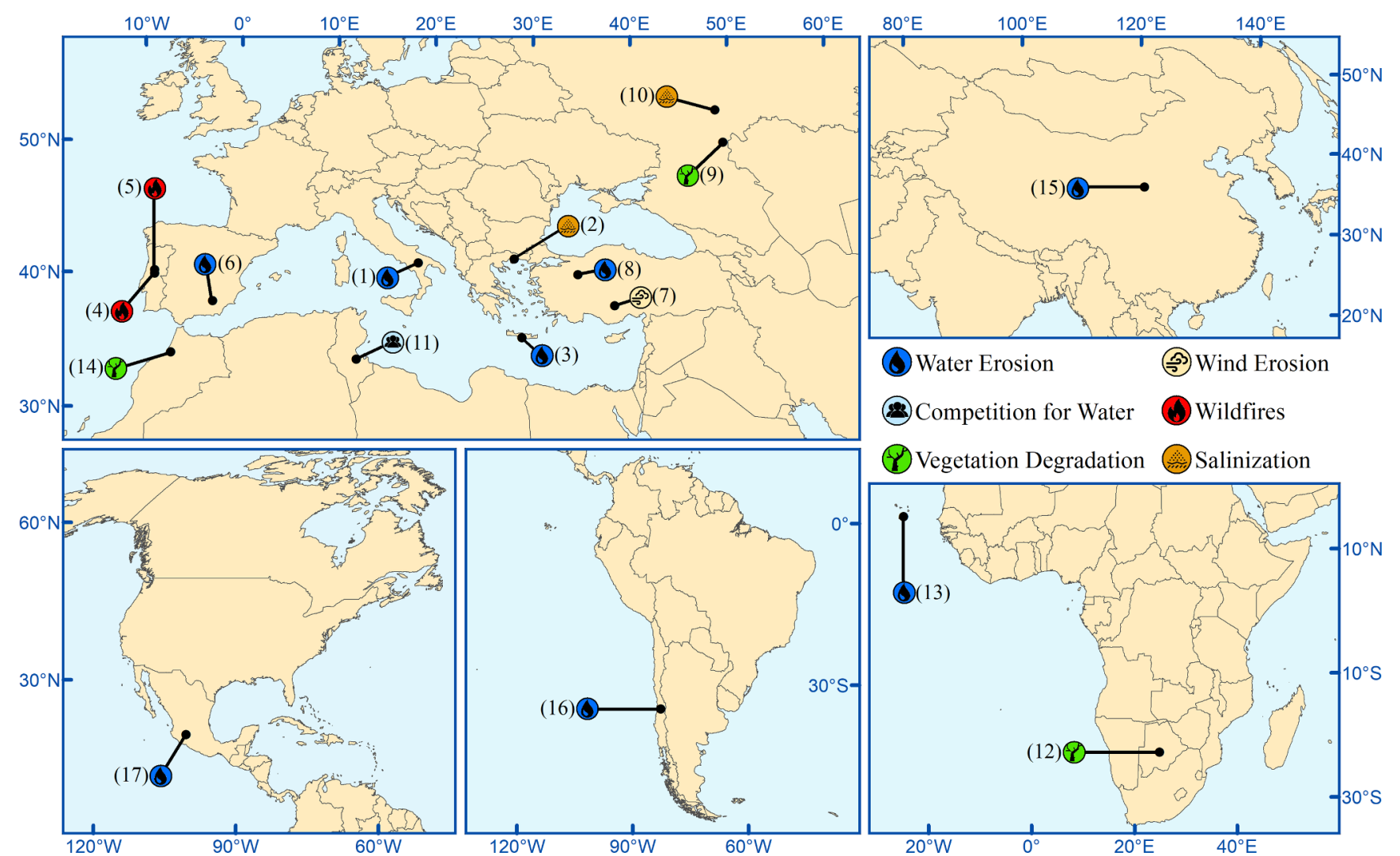

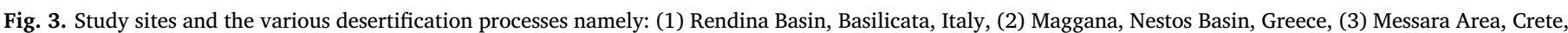

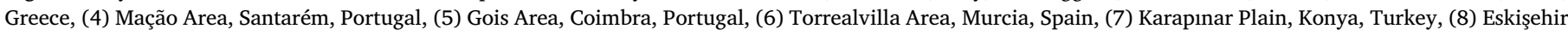

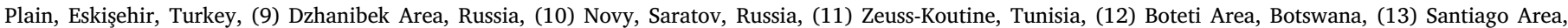

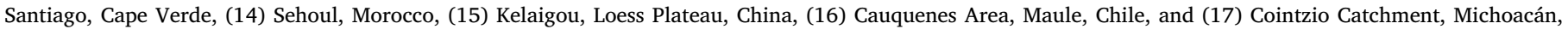
Mexico. 


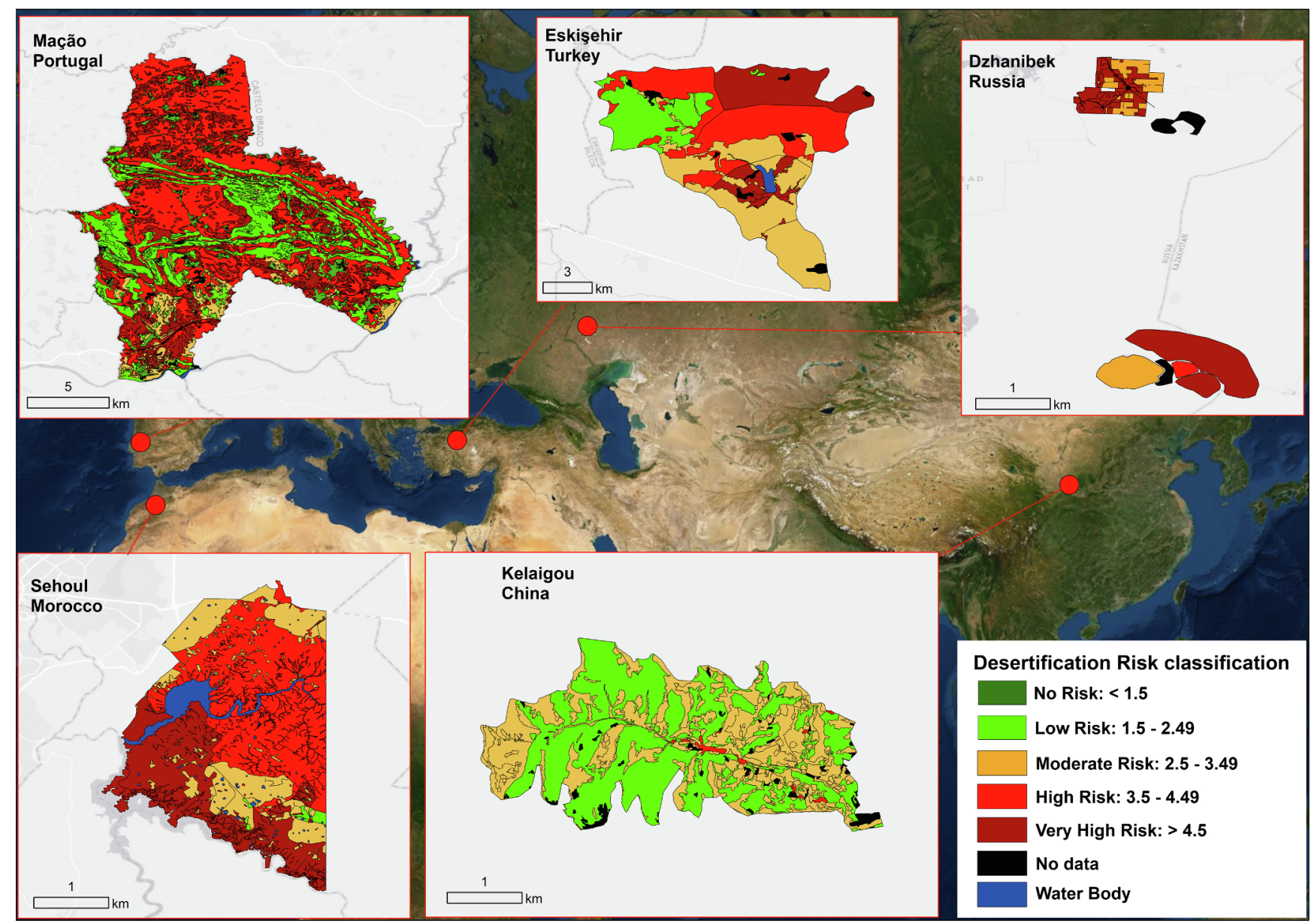

Fig. 4. Desertification risk in Mação (Portugal), Sehool (Morocco), Kelaigou (China), Eskişehir (Turkey), and Dzhanibek (Russia).

various risk values in between the above-mentioned integer numbers, the ES visualization used ranges of values from 1 to 5 as portrayed in the legend of Fig. 4. Overall, the concept of desertification risk underlines the exposure to desertification. Then, it may lead towards an estimate of the vulnerability to desertification, if land, social, economic, and management practices impacts are assessed. Moreover, the approach may define the encountered phases of desertification. Such phases were categorized and evaluated by climate, vegetation, soil, and management indicators that are new, existing ones, and those already incorporated from the antecedent methodology of ESAs. As pointed out, the ESA system has been extensively employed in the Mediterranean area and other similar locations (Benabderrahmane and Chenchouni, 2010; Parvari et al., 2011; Salvati et al., 2007; Tsesmelis et al., 2019a). However, since it has been developed following the DPSIR approach, the impacts on the state variables are usually multifaceted and interrelated and they may have different outcomes subject to the state indicators that are employed to describe those (Kosmas et al., 2003). Hence, a new combined system of indicators was essential to be developed in order to portray and evaluate the desertification risk according to physical characteristics, environmental ramifications, as well as the social, economic, and land management conditions. The next step was to run the stepwise multiple regression analysis with the desertification risk as the dependent variable and the candidate indicators assigned for each driver (process) as independent variables. The following linear equation was utilized (Steel et al., 1996):

$\mathrm{Y}=\beta_{0}+\beta_{1} \mathrm{X}_{1}+\beta_{2} \mathrm{X}_{2}+\cdots+\beta_{\kappa} \mathrm{X}_{\kappa}$

where $Y$ is the dependent variable, $\beta_{0}$ is the $\Upsilon$ intercept, $\beta_{1}, \beta_{2} \ldots \beta_{\kappa}$ are the slopes of the regression plane, and $X_{1}, X_{2} X_{\kappa}$, are the independent variables. Kosmas et al. (2014) give in detail the significant beta values of the stepwise linear regression for every indicator and for the algorithms processes assessing desertification risk. The majority of the indicators defining desertification risk were related to a combination of the physical characteristics (water, soil, vegetation, and climate), land management, social, and economic conditions in each sampling point. This resulted from the "effective" indicators influencing desertification risk in the various land uses that were related to the following land degradation and desertification drivers (Kosmas et al., 2014): agricultural areas-water erosion, pastures-water erosion, forested areas-water erosion, agricultural areas-tillage erosion, agricultural areas-soil salinization, agricultural or natural areas-water stress, pastures-overgrazing, and natural areas-wildfires. Fig. 1 portrays the flow among such land uses, processes, causes of land desertification and the number of effective indicators retained after the described statistical assessment for each degradation process. The next step was to incorporate the selected indicators and methodology from Kosmas et al. (2014) to a Drought Risk Assessment Tool (DRAST).

\subsection{Decision support tool development}

DRAST was developed as an expert system. It was created to provide an estimation of land desertification risk through the selection of the corresponding degradation processes and the pertinent indicators. The first step was to develop the corresponding equations in the form of Eq. (1), in order to estimate the desertification risk for distinct degradation processes in the predominant land uses, incorporating the created indicator database (Kosmas et al., 2014). DRAST includes all the identified indicators to suit a full spectrum of local physical, social, and 
economic conditions. Moreover, it helps assess the efficiency and efficacy of different land management practices in various land uses and landscapes vulnerable to desertification (Kairis et al., 2014; Kosmas et al., 2014). In an effort to demonstrate its applicability, the expert system was applied to case studies using data from the World Overview of Conservation Approaches and Technologies - Mapping Questionnaire (WOCAT QM) database (WOCAT et al., 2008). The WOCAT QM database was independently generated from data collected with different protocols than those used to develop the indicators database at another task of the DESIRE project (Schwilch et al., 2012). This approach was chosen in order to avoid autocorrelation problems, since the indicator-filled database was already used to develop the coefficients of the linear models used to assess the land desertification risk. The Desertification Risk Index (DRI) values, which are the output of DRAST, were color-coded as described in detail on the following sections and they are visualized in the pertinent maps. The overall methodological steps and framework are delineated in Fig. 2. This methodology evaluates the applicability of the developed risk desertification index.

It is believed that the applied methodology offers a series of appropriate and efficient indicators that could aid farmers, stakeholders and decision-makers to detect where land desertification is an existing or a potential threat, and which may be the options to alleviate such an issue at a given time period. For the DRAST utilization the following steps have to be followed: (a) select the suitable land use (agriculture, forest, or pasture); (b) methodologically determine the land degradation drivers-processes as tillage erosion, water erosion, soil salinization, etc., so to derive the corresponding relation from equation (1); (c) input the data to compute the values of the corresponding indicators and then introduce such values to the developed distinct equation; and (d) compute the DRI. The user has the option to change the input values of the indicators pertained to any land use and/or land management practices and to visualize alternative options or scenarios. DRAST has two versions, one produced to run on a Windows operating system and the other as a web-based tool. The architecture and the description of both versions are presented in the following sections. In both versions, an effort was made to develop a user-friendly and self-explanatory ES, which systematically step-by-step guides the user.

\subsubsection{Windows operating version}

The standalone version of DRAST with all the corresponding files is freely available and included in the deliverables of the EC DESIRE project (http://www.desire-his.eu/en/assessment-with-indicators/ desertificationrisk-assessment/570-offline-desertification-risk-

assessment-tool). The ES was developed using the Visual Basic.NET (VB.NET) VB 11.00 (2012). The Windows operating version produces the main screen shown in the background of Fig. 1A in the Appendix A. The main screen contains the following menus: -File - for saving and opening of the sessions; -Option - for selecting a type of erosion-degradation processes; -Indicators - for defining Indicator values and viewing results; -Help - for information related to DRAST application and instructions for use. Each menu consists of the corresponding actions, explained in detail in the Help file. The Option menu contains the Land Use-Degradation Processes Selection command. The Land UseDegradation Processes Selection opens a dialog box, where all the pertinent land use-degradation processes for the specific case should be selected by clicking on the appropriate boxes. The selection of the required Degradation Processes is saved by clicking on the OK button. A message box appears which indicates the next step as also shown in Fig. 1A. The Indicators menu is the main menu for the Desertification Risk Assessment. It consists of the following modes: (1) Calculate - The dialog box for the Indicators input Appendix A, Fig. 2A) and (2) View the dialog box to view and export the results (Appendix A, Fig. 3A). The selection of indicators for Desertification Risk Assessment is performed through the Calculate dialog box. The pre-selected Land Use-Degradation Processes activate the corresponding indicators, which are automatically included in the calculation of significant indicators per process and are ticked by the system in the view screen (Fig. 3A). It is noted that the number of indicators depends on the selection of degradation processes and it may vary from 8 to 17 for the individual processes (as indicated in Fig. 1). If several processes are assessed simultaneously, the number can be considerably higher. For example, 40 indicators are needed to assess water erosion (all three processes), tillage erosion, and water stress. Dialog boxes are available for each indicator that guides the user to assign the corresponding class based on its value. The various indicator value ranges and classes are included in the ES. For example, if water erosion, tillage erosion, and water stress degradation processes have been selected, then, some of the corresponding indicators values are presented in a form of the calculate dialog box (Appendix A, Fig. 2A). To offer an initial evaluation to the user, when selected, neutral indicator values are shown with white background, values contributing to high desertification risk are marked with red and values causing a low desertification risk with a green background. The View interface presents the results of the calculation of the effective indicators per process for Desertification Risk Assessment. A recalculate button is also provided for updating the results after performing changes in the selection of indicators. Fig. 3A presents an example of one calculation where all the degradation processes are selected except soil salinization. Thus, soil salinization process has a zero value assigned, since it is not selected, and the Desertification class risk field is empty and without color.

\subsubsection{Web-based tool version}

The system is loaded on the website: desire.aua.gr. The main screen gives the user the option to go through a comprehensive set of information regarding the tool and the EC DESIRE project. The menu on the left hand-side of the main page prompts the user to select between: (a) introduction of the tool, (b) information about the work carried out in DESIRE Project, (c) the applicability of the developed methodology, (d) the description of effective indicators affecting DRI, (e) general information about the tool, (f) the processes and causes of land degradation and desertification, $(\mathrm{g})$ the application of the DRI software, and $(h)$ pertinent references. The user starts a DRI estimation session by selecting the menu application in the DRAST software. As in the Windows operating version of the tool, in order to assess desertification risk, the user is prompted to select from various processes or causes of land degradation. Similarly, a new window is shown with the list of relevant indicators. Again, the number of the included indicators depends on the selected process, as has been previously explained.

After inserting the values for all the indicators, the DRI and all the indicators' classes are produced (Appendix A, Fig. 4A). The user maintains the option to go back and change any of the previously inputted indicators' value per process and to recalculate the DRI with the corresponding classes. The web-based tool does not provide a chart like the Windows-based operating based application. Therefore, the webbased expert system gives only a quick and handy assessment of the efficiency of various management practices to combat desertification.

\subsection{Desertification risk assessment tool application}

The presented methodology to describe land desertification risk by employing indicators was indicatively assessed on a smaller scale using independently collected data on soil organic matter content and erosion. These data were collected in the DESIRE study sites in Crete Island, Greece during the course of the project (Kosmas et al., 2014). In this context, the collected indicator data originated from the same country, thus, they exhibited no significant variation particularly for 
the indicators depicting social and economic conditions. The delineated DESIRE methodology was created using data from a whole spectrum of natural, environmental, social, and economic conditions worldwide (Kosmas et al., 2014; Kairis et al, 2014; Hessel et al., 2014; Schwilch et al., 2012). In this regard, the indicators data gathered could not be inserted for the DRAST evaluation, as they were already utilized for its creation. Hence, the use of independent databases was necessary. The DESIRE project had 17 study sites located in areas prone to desertification in various locales around the world (Fig. 3). For the indicators development, in all the study areas, field surveys were performed in various land uses such as cereals, almonds, vineyards, olive groves, cotton, deciduous forests, pine forests, and pastures to acquire pertinent indicators values at more than 1100 sampling points (DESIRE, 2012; Kairis et al., 2014; Kosmas et al., 2014). The study sites exhibited a plethora of natural, environmental, social, and economic characteristics (Hessel et al, 2014; Kosmas et al., 2014; Kairis et al, 2014). They are locales suffered by or being vulnerable to desertification due to a variety of processes, such as water stress, overgrazing, soil salinization, wildfires, and urbanization. These processes usually combined and exacerbated by the erosive power of water and air are ultimately leading to land desertification. However, the selected study site of Karapinar Plain, Konya, Turkey could not produce reliable wind erosion data, as stated, and thus, since aeolian erosion was not encountered in the other study sites the pertinent indicators have been excluded.

In this context, the DRI computation and evaluation was achieved using independent databases from two distinct approaches. The first approach contained indicator values computed for every site, using the independent WOCAT QM database (Fig. 2), which is also a product of the DESIRE project (Hessel et al., 2014; Schwilch et al., 2012; WOCAT et al., 2008). The DRI estimation was performed for all the 17 DESIRE case study areas as presented in Fig. 3. However, given the current effort constrains, for the various desertification process, five representative case study areas were chosen among the DESIRE case study sites to be illustrated. Thus, the desertification processes and assessment results are presented for these case studies including: Sehoul, Morocco (high- pressure agriculture and overgrazing resulting in water erosion), Mação, Portugal (wildfires and water erosion), Kelaigou, China (tillage practices resulting in increased water erosion), Eskişehir, Turkey (increasing water erosion in: pastures and shrubs, forests, and agricultural lands), and Dzhanibek, Russia (overgrazing, salinization, and water stress) as seen in Table 1. The indicator estimation started by using data from the WOCAT QM database. Then, from the depicted in the WOCAT QM database land use system (LUS), land degradation and sustainable land management (SLM) information as defined for each map unit were retrieved. The starting point for mapping degradation and conservation is land use and land management. Thus, according to the WOCAT procedures, a base map unit is defined by the land use type, then subdivided by crop type as well as geomorphologic processes, and administrative and socio-economic criteria. Furthermore, a map unit is not necessarily limited to a single closed polygon, but it may include several larger and smaller polygons, together establishing a map unit for which degradation and conservation options need to be assessed. The number of mapping units should be more or less similar for all study sites. Each study site should have a number of 30-100 units for which information needs to be inserted to the corresponding matrix tables. Overall, the size of the site and the variability within the area decided the scale of the mapped results and the size of the mapping units (DESIRE, 2012). In the map units with two or more degradation processes, the dominant process was chosen for the entire unit as required by the WOCAT QM database (DESIRE, 2012; Schwilch et al., 2012). Then, the corresponding data were converted into indicators values according to the assigned indicator classes and weights following the harmonized indicator database guidelines (Kairis et al., 2014; Kosmas et al., 2014).

The second approach is to apply and evaluate DRAST as presented by Jetten (2012), using field level experimental results performed in all

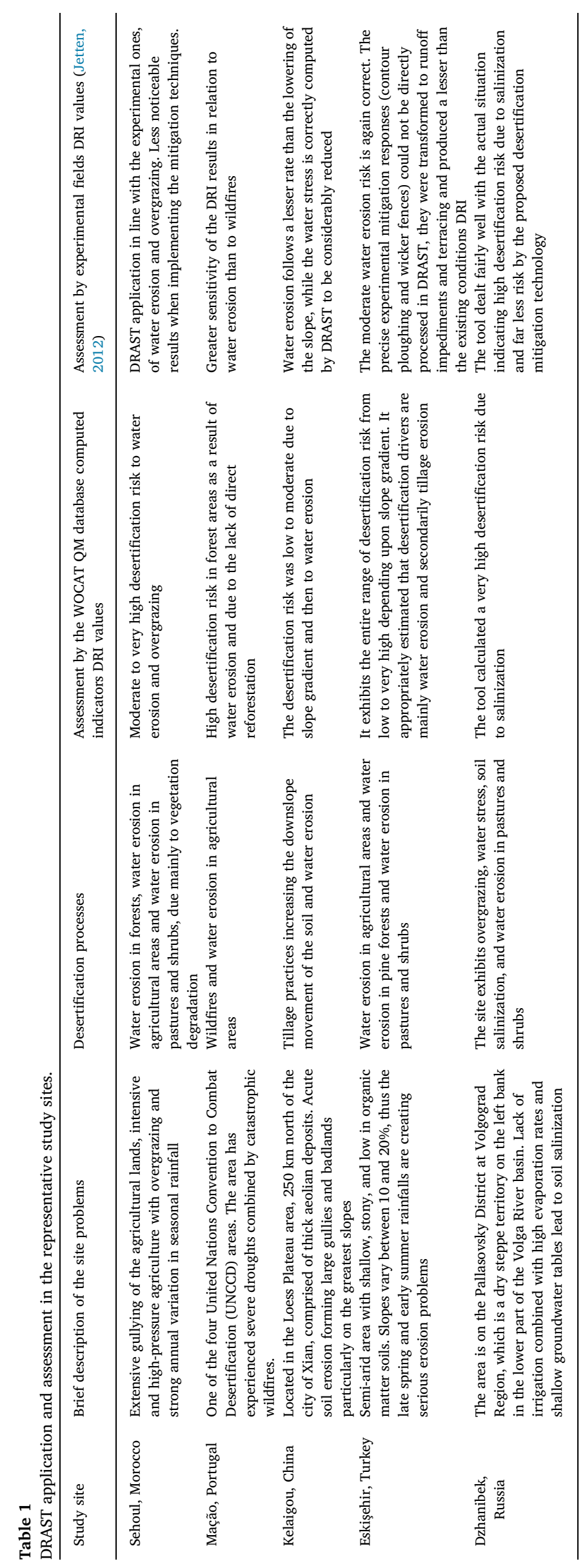


the DESIRE study areas apart from the Rendina site in Italy, where local social conditions prohibited such an application. Thus, DRI values were computed in every participating experimental site using the existing conditions, and then, DRI values were generated after the application of the mitigation experiments. Subsequently, the differences in desertification risk were assessed against the general outcomes, which in some cases it was an indirect comparison due to the nature of the variable's transformation (local to regional ones). The results from the local field experiments were fed into DRAST in order to pinpoint pitfalls and provide guidance for potential future improvements of the tool. Nevertheless, it is noted that DRAST is applied on a field level mostly out of context, since the tool is not designed to assess individual experiments on a field/plot scale. The DRI method is based on parameters across all the sites and on more regional variables that may not be affected at an experimental scale (Jetten, 2012). The methodological steps followed were straightforward and uncomplicated: in every site and as the first step, the tool has been used to calculate the desertification risk index of the existing conditions. Then, all experiments focused on mitigating land degradation and desertification on a site were incorporated. After that, the difference in DRI was computed and the DRAST performance evaluated. For the application, some field data translation occurred in order to insert certain localized field conditions into the parameter settings of DRAST.

\section{Results}

The process to calculate DRI began by identifying the land use degradation process. For the principal evaluation approach, which uses the WOCAT database as described, the pertinent indicators were estimated and inserted into DRAST and the tool calculated DRI for every map unit. Overall, more than 3000 indicators in 382 map units were calculated. For the selected and presented five case study areas, 912 indicators in 70 map units were assigned and their corresponding values were computed. Key characteristics of the application procedure for each study site are summarized in Table 1 . Then, the DRI values for every map unit were portrayed in a scale and all the results were pictured in pertinent maps including their scale and color classification scheme (Fig. 4). For the second experimental fields approach, the results for all the presented sites are summarized in Table 1 .

\section{Discussion}

Overall, the results seem to reflect well with the regional variables used. The evaluation on a regional scale using the WOCAT generated data as the input provided good and appropriate outcomes. Such results offer an initial assessment of desertification risk showcasing which areas need the most immediate desertification mitigation measures. At this point, it is again noted that Jetten (2012) has also presented an evaluation of the DRAST with the existing conditions and after the experimental mitigation measures on a field scale for 16 of the 17 case sites. Overall, Jetten (2012) reported that the results are appropriate; the tool shows what it is supposed to show namely that risk becomes lower than the one initially existing, in accordance with the experimental implementation of desertification mitigation responses. As the risk index is produced using multivariate statistics, both the initial computed risk and the change of risk after the implementation of desertification mitigation responses is relatively less than the experimental results usually show. Such a fact is logically expected, since DRAST applies a "mean" of all the study areas and the outcome of pertinent mitigation measure is less prominent on regional than on field level.

\subsection{DRAST advantages}

As pointed out, DRAST was applied and evaluated for all the 17 DESIRE case study sites, including the five areas presented. This approach and the produced indicators were created based on datasets collected under specific protocols, as described by Kosmas et al (2014). Thus, for the DRAST assessment another independent database had to be used, as previously stated. The WOCAT QM methodology provided maps of land degradation status and existing trends using its own specific protocols of individual expert judgement assessment (WOCAT et al., 2008). In this effort, more qualitative estimates and data translations had to be involved in order to utilize the existing available data input for DRAST from the WOCAT QM database. Despite the differences in the approach, the resulted maps of the DRI by the DRAST application provided similar information as the original maps of the WOCAT QM methodology (Schwilch et al., 2012). Thus, DRAST seems robust enough to produce appropriate risk estimations, if quantitative data as the indicator database described by Kosmas et al (2014) are present, but also when such data are not in abundance and thus having to derive reasonable approximations. Even the use of data and information of a different scale (field-specific instead of regional), as in the Jetten (2012) application, has shown that it describes more than adequately the desertification risk. However, in both cases, the results are transferring the corresponding degree of uncertainty. Overall, creating a completely quantitative indicator dataset is often a labor-intensive effort; hence, it may be a plus that the approach could also be applied with less detailed and more qualitative input datasets. Jetten (2012) also states that the tool is very adaptable and parameters that are not available in an area can be omitted, so it can be easily adjusted to the locally existing data. He has also pointed out that the tool generally does what it is expected to do, and the risk variables reflect well the experiments performed. Thus, the tool may also be utilized in data poor areas allowing land use managers worldwide to have a handy initial estimate of a particular mitigation option on the desertification risk per se. In other words, using it as a quick and handy decision-making tool.

A crucial additional element is to comment on the performance of the individual indicator's behavior pertaining to the DRAST application. In this regard, the most pronounced comparative result is that in almost all the study sites the indicator annual rainfall amount was not a factor influencing water stress risk, as much as the already described as a very important indicator of rainfall seasonality (Kosmas et al., 2014). Such a fact was also delineated in the indicator development phase (Kairis et al., 2014). In this context, water stress may be generated in an area having more than $1500 \mathrm{~mm}$ of average annual rainfall, and no water stress in an area with less than $280 \mathrm{~mm}$ of average annual rainfall. At this point, it should noted that water stress is strongly related to water demand (Karavitis et al., 2014; Wu et al., 2007; Yevjevich et al., 1983). For example in many of the Mediterranean countries (Greece, Spain, Tunisia, Italy, South-western Turkey, etc.), the majority of the precipitation falls during the winter months, when the water demand is very low due to the minimal agricultural activities, low tourist needs, less urban water consumption, etc. On the contrary, in the summer months when there is high irrigation and tourism is in full swing, precipitation is often close to zero. Thus, rainfall seasonality is central. For example, if the majority of an average annual rainfall of $1500 \mathrm{~mm}$ falls during the winter months, it may have minimal impacts and uses, and through runoff it may end up mostly unused in the various water bodies. Furthermore, the first usually intense rainfall events after the hot dry summer season often result in flooding with considerable erosion and desertification problems of already scorched lands. Rainfall seasonality is an additional reason for the construction of dams and reservoirs in these areas, in order to store the winter excess water and 
use it during times of high demand and limited precipitation in the summer. Moreover, it is also an attempt to simultaneously control floods and erosion (Karavitis et al., 2014, 2012; Tsakiris and Vangelis, 2004). On the other hand, in an area where the majority of the $280 \mathrm{~mm}$ precipitation coincides with the period of high demand water use, less water stress will be expected, and the corresponding indicator will more closely reflect the regional character. Thus, DRAST based on the performed indicator analyses is promptly portraying the importance of rainfall seasonality for desertification risk assessment (Jetten, 2012; Kairis et al., 2014; Kosmas et al., 2014).

\subsection{DRAST limitations}

DRAST is performing at its best when a set of quantitative indicators are used. However, certain limitations may be surfaced, when it is used as stated, with more qualitative data. In this case, the quality of the results is directly reflected to the quality of the transformation of the qualitative information to quantitative indicators. Another point is that the tool does not include wind erosion indicators, thus it cannot be applied to aeolian erosion suffering areas for estimating desertification risk. Additionally, land conservation measures indicators are not included, and such measures may be introduced indirectly through the most relevant indicators. Furthermore, it is more appropriate if applied in the spatial context of a region and greater. Its application in a field scale is less accurate; however, it may present more than adequately the desertification risk. As DRI is a product of the inserted indicators, the user sees only the final computed value. The individual sub-products of each parameter are not shown and thus it cannot portray which parameter/indicator effects more than the others do the calculated DRI value. Finally, it should be applied with caution in the southern hemisphere, since seasonality corrections were not included for these climates.

\subsection{Future research needs}

In regards to future research needs, Jetten (2012) proposes that a future development of the indicator based tool should: (1) include conservation measures in the indicators datasets, and (2) display comparably the relative importance of the parameters, so that it is clear which parameter influences more the results. This may help to understand how DRI is produced and how significant the effect of a desertification mitigation response would be to produce a difference, specifically a sought decrease in risk. Nevertheless, such data on appropriate management measures should be a part of a larger future research effort in order to demonstrate how the choice of certain measures changes the values of certain indicators, and how this impacts desertification risk. In this line, a future research effort should also incorporate sites exhibiting wind erosion problems to test if relevant indicators may be introduced. Up to then DRAST may be applied in areas, where desertification has all the other drivers/causes apart from those of aeolian origin. Finally, another point to be noted may be that since indicator data from the southern hemisphere (Chile) were also used for the indicator methodological application, future research efforts should include seasonality corrections for such climatic zones.

\section{Conclusions}

The presented methodology for the Decision Support Tool creation was accomplished incorporating data from a wide spectrum of natural and anthropogenic environments, on a worldwide scale. The use of two different databases, one for development and one for testing may also contribute to the originality and applicability of the whole effort. As a result, the presented DRAST application outcomes may illustrate that the tool is practical in assessing desertification risk at a plethora of locales with a variety of physical, environmental, social, and economic characteristics. In addition, the application of the methodology in areas beyond the Mediterranean ones was largely successful and produced very good results. Generally, to fully utilize the pertinent approach, it may be advisable to have datasets for most of the assigned indicators in each desertification process. However, if the available data are poor or limited, existing similar datasets may be transformed into the corresponding indicators and then applied to DRAST, producing also dependable outcomes. The tool can be utilized for desertification monitoring techniques and to assess the results of desertification combating measures both at field level and at regional level. The developed ES may also enable stakeholders and end users to assess different future scenarios for desertification risk aversion and at the same time to evaluate critical stress parameters, their impacts and consequently it may indirectly to evaluate desertification vulnerability. Thus, DRAST may allow end users and decision-makers to produce dependable, timely, and efficient desertification mitigation responses. It may also assess how desertification risk transforms, if pertinent management options are applied. For such an assessment, DRAST has the following advantages particularly for environmental management: (1) demonstration, computation, visualization, and assessment of a variety of desertification indicators; (2) presentation of the resulting DRI in a concise, comparable, reproducible, and holistic fashion; (3) direct sensitivity of the input to the associated output; and (4) multidisciplinary criteria and assessment process by incorporating experts, administrators, professionals, farmers and decision makers.

Future research efforts may also lead to include additional conservation/mitigation indicators and help to trim application inconsistencies. The incorporation of aeolian erosion indicators should also be sought. Overall, a future DRI application in pilot areas with a benchmark problem and pertinent reliable databases may help pinpoint potential pitfalls and implementation incongruities. Finally, effective development and application of DSSs for desertification mitigation and generally for natural resources management, requires flexible adaptive options accompanied by corresponding institutions of scale and character. Such a combination may lead to a successful implementation in an evolving, complex, and fast-changing physical and anthropogenic environment. Above all, timely and efficient implementation of the DSS outcomes, calls for an incorporation of the produced management options in a policy framework having its foundations on a well-structured participatory process involving experts, end users, stakeholders, and decision makers.

\section{Declaration of Competing Interest}

The authors declare that there is no known conflict of interest.

\section{Acknowledgements}

The research described in this paper was conducted within the framework of the European Commission- Directorate-Generalfor Research and Innovation (DG RTD) 6th Framework Research Programme, Global Change and Ecosystems (sub-priority 1.1.6.3), project DESIRE (Code: F6 DG RTD 037046): Desertification Mitigation and Remediation of Land - a global approach for local solutions. 


\section{Appendix A}

See Figs. 1A-4A.

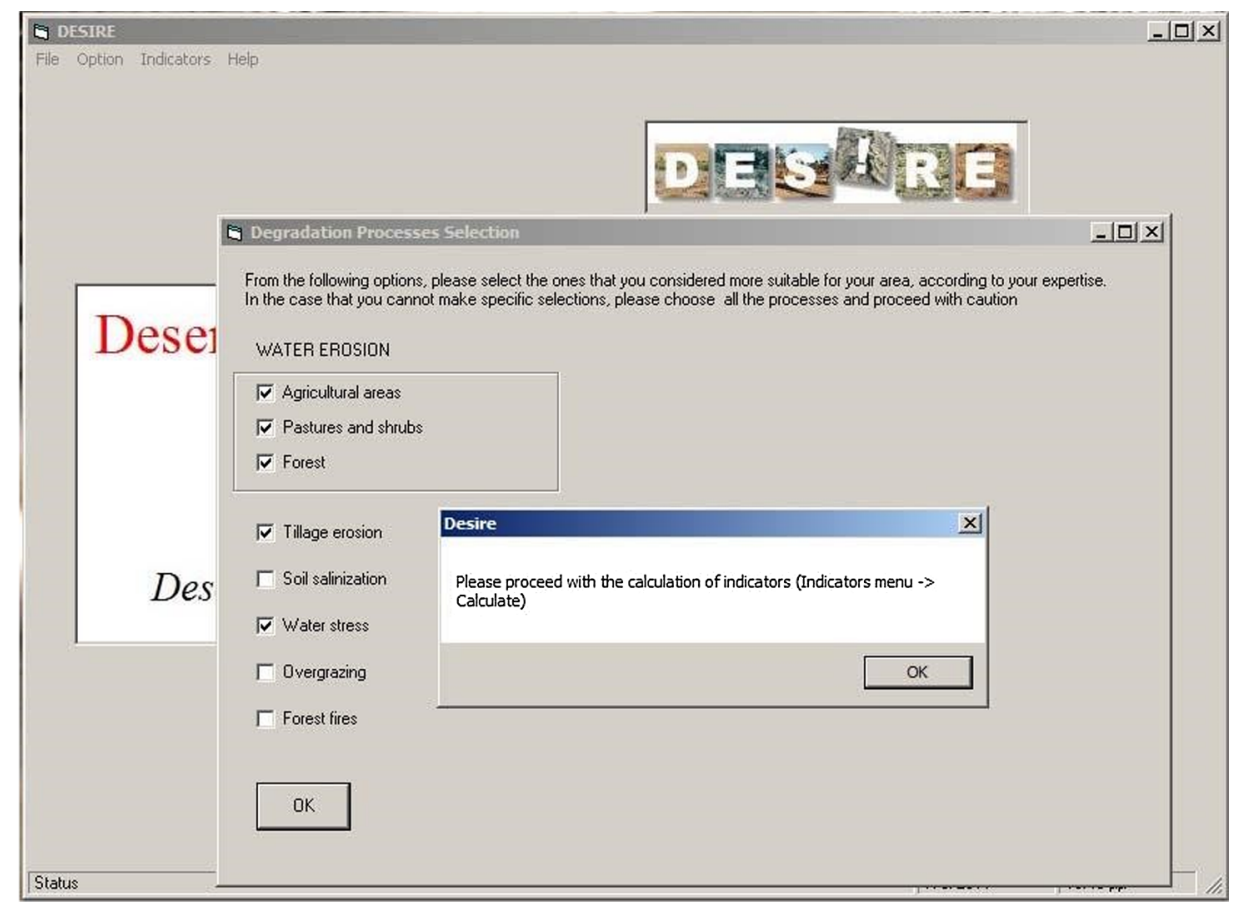

Fig. 1A. Degradation processes selection interface.

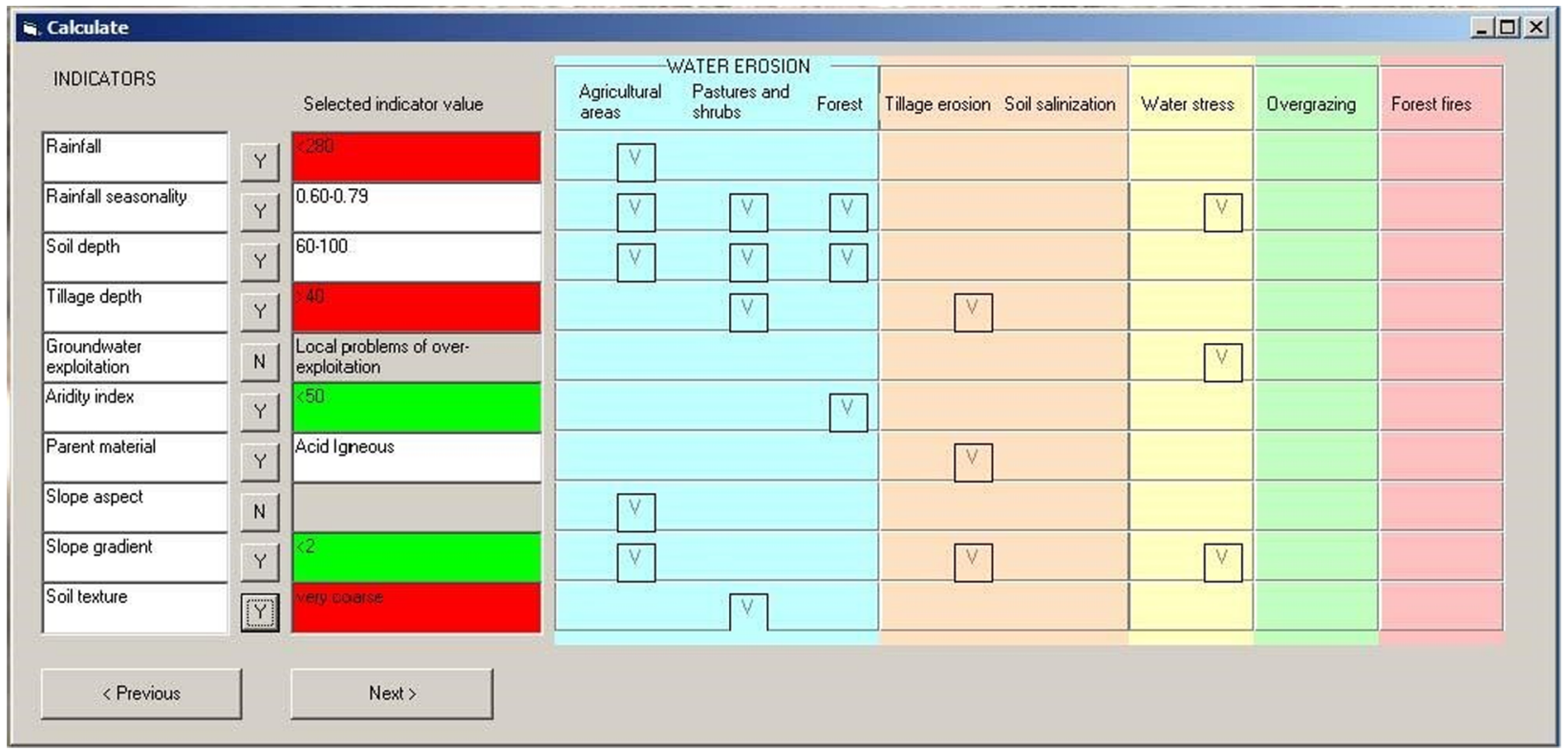

Fig. 2A. Calculate dialog box interface with the pertinent indicators per desertification process. 


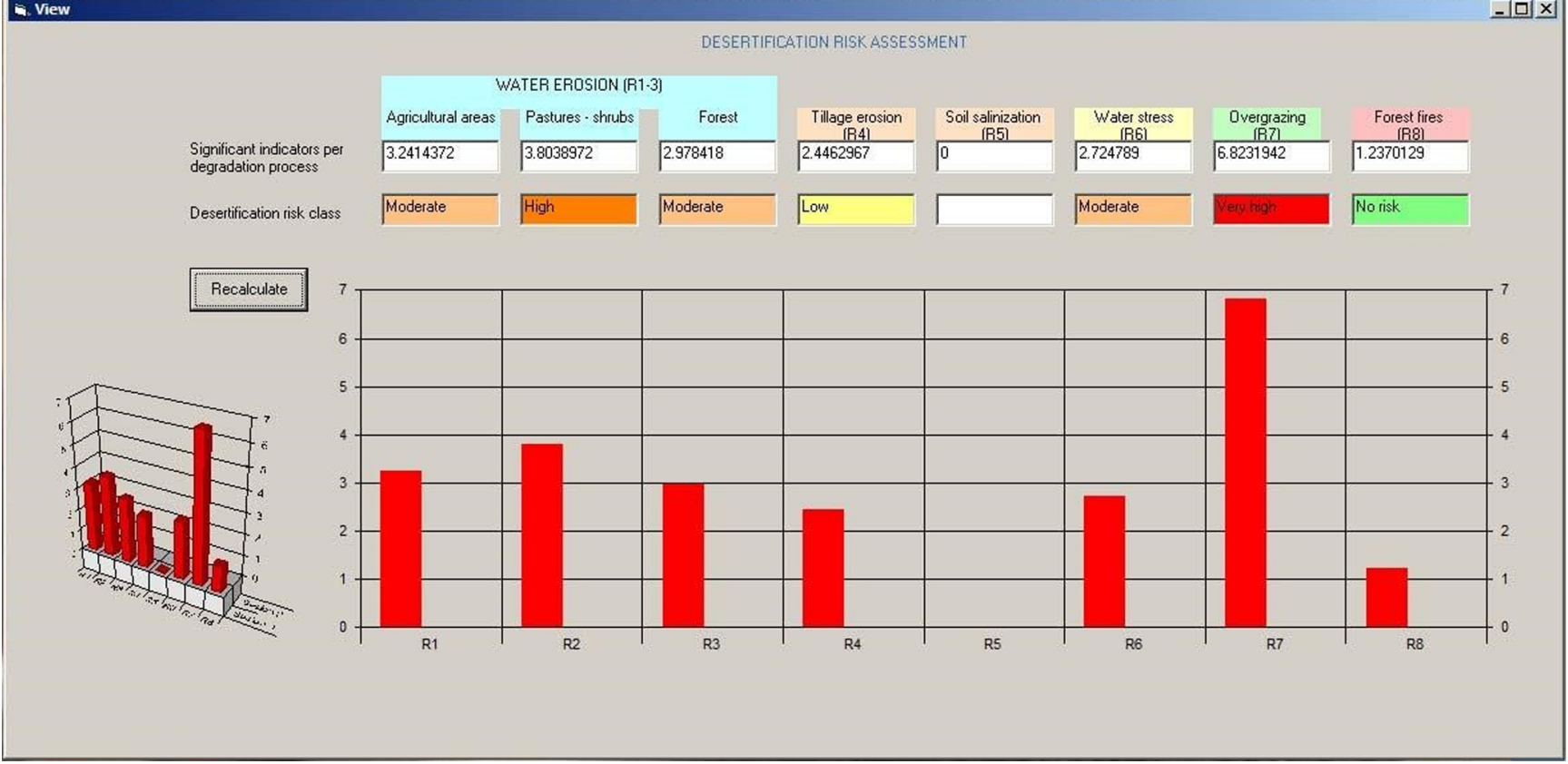

Fig. 3A. Outputs interface with the calculated desertification risk index and the corresponding categories.

TITLE

\begin{tabular}{|c|c|c|c|c|}
\hline SELECT DEGRADATIONS & RESULTS & & & \\
\hline \multicolumn{5}{|c|}{ CALCULATE } \\
\hline & - & & & Water stress \\
\hline Rain seasonality & & $0.60-0.79$ & $\checkmark$ & $\frac{3.0338744}{-}$ \\
\hline \multicolumn{2}{|l|}{ Ground water exploitation } & Exploitation»recharge & $\checkmark$ & - \\
\hline \multicolumn{2}{|l|}{ Parent material } & other & $\checkmark$ & - \\
\hline \multicolumn{2}{|c|}{ Distance from seashore or other salty water bodies $(\mathrm{Km})$} & $<0.25$ & $\checkmark$ & - \\
\hline \multicolumn{2}{|c|}{ Runoff water storage } & adequate & 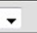 & - \\
\hline \multicolumn{2}{|c|}{$\begin{array}{l}\text { Water scarcity (Water available supply per capita / water consumption per } \\
\text { capita during the last } 10 \text { years) (WAC/WCC }=\mathrm{R} \text { ) }\end{array}$} & Moderate $R=1-1.5$ & $\checkmark$ & - \\
\hline \multicolumn{2}{|l|}{ Population density } & Moderate 50-100 & $\checkmark$ & - \\
\hline
\end{tabular}

Fig. 4A. Interface with the calculated desertification risk index and the corresponding classes.

\section{References}

Basso, F., Bove, E., Dumontet, S., Ferrara, A., Pisante, M., Quaranta, G., Taberner, M., 2000. Evaluating environmental sensitivity at the basin scale through the use of geographic information systems and remotely sensed data: an example covering the Agri basin (Southern Italy) Funded by MEDALUS III EEC Project. CATENA 40, 19-35. https://doi.org/10.1016/S0341-8162(99)00062-4.

Benabderrahmane, M.C., Chenchouni, H., 2010. Assessing environmental sensitivity areas to desertification in Eastern Algeria using mediterranean desertification and land use "MEDALUS" model. Int. J. Sustain. Water Environ. Syst. 1, 5-10. https://doi.org/10. 5383/swes.01.01.002.

Brandt, J., Geeson, N., 2005. Desertification information system to support National Action Programmes in the Mediterranean (DISMED). DIS4ME, Desertification Indicator System for Mediterranean Europe. Eur. Environ. Agency.

Briassoulis, H., 2019. Combating land degradation and desertification: the land-use planning quandary. Land 8, 27. https://doi.org/10.3390/land8020027.

Briassoulis, H. (Ed.), 2005. Policy Integration for Complex Environmental Problems: The Example of Mediterranean Desertification. Routledge, Farnham, Surrey, GB.

DESERTLINKS, 2004. Combating desertification in Mediterranean Europe: linking science with stakeholders (No. European Commission Grant agreement ID: EVK2-CT-200100109).
DESIRE, 2012. Desertification Mitigation and Remediation of land - a global approach for local solutions. (No. European Commission Grant agreement ID: 37046).

Enne, G., Zucca, C., 2000. Desertification indicators for the European Mediterranean region: state of the art and possible methodological approaches. National Environmental Protection \& Nucleo di Ricerca sulla Desertificazione, Università degli Studi di Sassar, Rome.

Fierotti, G., Zanchi, C., 1998. Agricultural practices and soil fertility degradation. In: Enne, G., D’Angelo, M., Zanolla, C. (Eds.), Indicators for Assessing Desertification in the Mediterranean. Proceedings of the International Seminar held in Porto Torres, Italy, 18-20 September 1998, pp. 101-115.

Finke, P., Hartwich, R., Dudal, R., Ibanez, J., Jamagne, M., King, D., Montanarella, L., Yassoglou, N., 1998. Georeferenced soil database for Europe, Manual of procedures, version 1. European Soil Bureau, Scientific Committee.

Genske, D.D., Heinrich, K., 2009. A knowledge-based fuzzy expert system to analyse degraded terrain. Expert Syst. Appl. 36, 2459-2472. https://doi.org/10.1016/j.eswa. 2007.12.021.

Hessel, R., Reed, M.S., Geeson, N., Ritsema, C.J., van Lynden, G., Karavitis, C.A., Schwilch, G., Jetten, V., Burger, P., van der Werff ten Bosch, M.J., Verzandvoort, S., van den Elsen, E., Witsenburg, K., 2014. From Framework to Action: The DESIRE Approach to Combat Desertification. Environmental Management 54, 935-950. https://doi.org/10.1007/s00267-014-0346-3.

Jetten, V., 2012. Evaluating the Desertification Risk Assessment Tool with experimental 
results. URL: http://www.desire-his.eu/en/assessment-with-indicators/ desertification-risk-assessment/898-evaluatingthe-desertification-risk-assessmenttool-with-experimental-results (accessed 1.27.19).

Kairis, O., Kosmas, C., Karavitis, C., Ritsema, C., Salvati, L., Acikalin, S., Alcalá, M., Alfama, P., Atlhopheng, J., Barrera, J., Belgacem, A., Solé-Benet, A., Brito, J., Chaker, M., Chanda, R., Coelho, C., Darkoh, M., Diamantis, I., Ermolaeva, O., Fassouli, V., Fei, W., Feng, J., Fernandez, F., Ferreira, A., Gokceoglu, C., Gonzalez, D., Gungor, H., Hessel, R., Juying, J., Khatteli, H., Khitrov, N., Kounalaki, A., Laouina, A., Lollino, P., Lopes, M., Magole, L., Medina, L., Mendoza, M., Morais, P., Mulale, K., Ocakoglu, F., Ouessar, M., Ovalle, C., Perez, C., Perkins, J., Pliakas, F., Polemio, M., Pozo, A., Prat, C., Qinke, Y., Ramos, A., Ramos, J., Riquelme, J., Romanenkov, V., Rui, L., Santaloia, F., Sebego, R., Sghaier, M., Silva, N., Sizemskaya, M., Soares, J., Sonmez, H., Taamallah, H., Tezcan, L., Torri, D., Ungaro, F., Valente, S., de Vente, J., Zagal, E. Zeiliguer, A., Zhonging, W., Ziogas, A., 2014. Evaluation and selection of indicators for land degradation and desertification monitoring: types of degradation, causes, and implications for management. Environ. Manage. 54, 971-982. https://doi.org/ 10.1007/s00267-013-0110-0.

Karavitis, C.A., 1999. Decision support systems for drought management strategies in metropolitan athens. Water Int. 24, 10-21. https://doi.org/10.1080/ 02508069908692129.

Karavitis, C.A., Chortaria, C., Alexandris, S.G., Vasilakou, C.G., Tsesmelis, D.E., 2012. Development of the standardised precipitation index for Greece. Urban Water J. 9, 401-417. https://doi.org/10.1080/1573062X.2012.690431.

Karavitis, C.A., Oikonomou, P.D., Waskom, R.M., Tsesmelis, D.E., Vasilakou, C.G., Skondras, N.A., Stamatakos, D., Alexandris, S.G., Grigg, N.S., 2015. Application of the Standardized Drought Vulnerability Index in the Lower South Platte Basin, Colorado. In: AWRA Annual Water Resources Conference Proceedings. Presented at the AWRA Annual Water Resources Conference, Denver, CO.

Karavitis, C.A., Tsesmelis, D.E., Skondras, N.A., Stamatakos, D., Alexandris, S., Fassouli, V., Vasilakou, C.G., Oikonomou, P.D., Gregorič, G., Grigg, N.S., Vlachos, E.C., 2014. Linking drought characteristics to impacts on a spatial and temporal scale. Water Policy 16, 1172-1197. https://doi.org/10.2166/wp.2014.205.

Kibblewhite, M., Rubio, J., Kosmas, C., Jones, R., Arrouays, D., Huber, S., Verheijen, F., 2007. Environmental assessment of soil for monitoring desertification in Europe, United Nations Convention for Combating Desertification, Madrid.

Kosmas, C., Danalatos, N.G., Gerontidis, S., 2000a. The effect of land parameters on vegetation performance and degree of erosion under Mediterranean conditions. CATENA 40, 3-17. https://doi.org/10.1016/S03418162(99)00061-2.

Kosmas, C., Gerontidis, S., Marathianou, M., 2000b. The effect of land use change on soils and vegetation over various lithological formations on Lesvos (Greece). CATENA 40, 51-68. https://doi.org/10.1016/S03418162(99)00064-8.

Kosmas, C., Kairis, O., Karavitis, C., Ritsema, C., Salvati, L., Acikalin, S., Alcalá, M., Alfama, P., Atlhopheng, J., Barrera, J., Belgacem, A., Solé-Benet, A., Brito, J., Chaker, M., Chanda, R., Coelho, C., Darkoh, M., Diamantis, I., Ermolaeva, O., Fassouli, V., Fei, W., Feng, J., Fernandez, F., Ferreira, A., Gokceoglu, C., Gonzalez, D., Gungor, H., Hessel, R., Juying, J., Khatteli, H., Khitrov, N., Kounalaki, A., Laouina, A., Lollino, P., Lopes, M., Magole, L., Medina, L., Mendoza, M., Morais, P., Mulale, K., Ocakoglu, F., Ouessar, M., Ovalle, C., Perez, C., Perkins, J., Pliakas, F., Polemio, M., Pozo, A., Prat, C., Qinke, Y., Ramos, A., Ramos, J., Riquelme, J., Romanenkov, V., Rui, L., Santaloia, F., Sebego, R., Sghaier, M., Silva, N., Sizemskaya, M., Soares, J., Sonmez, H., Taamallah, H., Tezcan, L., Torri, D., Ungaro, F., Valente, S., de Vente, J., Zagal, E., Zeiliguer, A., Zhonging, W., Ziogas, A., 2014. Evaluation and selection of indicators for land degradation and desertification monitoring: methodological approach. Environ. Manage. 54, 951-970. https://doi.org/10.1007/s00267-013-0109-6.

Kosmas, C., Kirkby, M., Geeson, N., 1999. Manual on: Key indicators of desertification and mapping environmentally sensitive areas to desertification (No. EUR 18882). Eur. Comm. Energy Environ. Sustain. Dev.

Kosmas, C., Tsara, M., Moustakas, N., Karavitis, C., 2003. Identification of Indicators for desertification. Ann. Arid Zone 42, 393-416.

Liniger, H., Schwilch, G., Gurtner, M., Mekdaschi Struder, R., Van Lynden, G., Critchley, W., 2007. Word overview of conservation approaches and technologies. A Framework for Documentation and Evaluation of Land Conservation.

López, E.M., García, M., Schuhmacher, M., Domingo, J.L., 2008. A fuzzy expert system for soil characterization. Environ. Int. 34, 950-958. https://doi.org/10.1016/j.envint. 2008.02.005.

MEDALUS III, 1996. Mediterranean desertification and land use. Project 2: target areas (No. European Commission Grant agreement ID: ENV4950119).

MEDRAP, 2004. Concerted action to support the northern Mediterranean regional action programme to combat desertification (MEDRAP) (No. European Commission Grant agreement ID: EVK2-CT-2000-20008). Centro Interdipartimentale di Ateneo Nucleo Ricerca Desertificazione Universita degli Studi di Sassari, Sassari.

Mohan, S., Arumugam, N., 1997. Expert system applications in irrigation management: an overview. Comput. Electron. Agric. 17, 263-280. https://doi.org/10.1016/S01681699(97)01309-4.

OECD, 2004. OECD Key Environmental Indicators 2004. Organization for Economic Cooperation and Development (OECD), Paris, France.

Oikonomou, P.D., 2017. Methodologies for Transforming Data to Information and Advancing the Understanding of Water Resources Systems towards Integrated Water Resources Management (Ph.D. Dissertation). Colorado State University, Department of Civil \& Environmental Engineering, Fort Collins, CO.

Oikonomou, P.D., Tsesmelis, D.E., Waskom, R.M., Grigg, N.S., Karavitis, C.A., 2019. Enhancing the standardized drought vulnerability index by integrating spatiotemporal information from satellite and in situ data. J. Hydrol. 569, 265-277. https://doi.org/10.1016/j.jhydrol.2018.11.058.

Oikonomou, P.D., Waskom, R.M., 2018. Assessing drought vulnerability in Northeast Colorado. AGU Fall Meet. Abstr. H51H-1404.

Parvari, S.H., Pahlavanravi, A., Moghaddam Nia, A.R., Dehvari, A., Parvari, D., 2011. Application of methodology for mapping environmentally sensitive areas (ESAs) to desertification in dry bed of Hamoun Wetland (Iran). ECOPERSIA 65-80.

Peters, D.P., Havstad, K.M., Archer, S.R., Sala, O.E., 2015. Beyond desertification: new paradigms for dryland landscapes. Front. Ecol. Environ. 13, 4-12. https://doi.org/10. $1890 / 140276$

Pulina, G., D’Angelo, M., Madrau, S., Zucca, C., Enne, G., 1998. Indicators of land use intensity in agropastoral ecosystems. In: Enne, G., D’Angelo, M., Zanolla, C. (Eds.), Indicators for Assessing Desertification in the Mediterranean. In: Proceedings of the International Seminar held in Porto Torres, Italy, 18-20 September 1998, pp. 177-185.

Recatala, L., Fabbri, A., Zink, J., Frances, A., Sanchez, I., 2002. Environmental indicators for assessing and monitoring desertification and its influence on environmental quality in Mediterranean environments. Man Soil Third Millennium, ESSC 1, 897-910.

Rubio, J.L., Bochet, E., 1998. Desertification indicators as diagnosis criteria for desertification risk assessment in Europe. J. Arid Environ. 39, 113-120. https://doi.org/10. 1006/jare.1998.0402.

Rykiel, E.J., 1989. Artificial intelligence and expert systems in ecology and natural resource management. Ecol. Model. 46, 3-8. https://doi.org/10.1016/0304-3800(89) 90066-5.

Salvati, L., 2012. The spatial nexus between population growth and land degradation in a dry Mediterranean region: a rapidly changing pattern? Int J Sustain Dev World Ecol 19, 81-88. https://doi.org/10.1080/13504509.2011.593007.

Salvati, L., Bajocco, S., 2011. Land sensitivity to desertification across Italy: past, present, and future. Appl Geogr Hazard 31, 223-231. https://doi.org/10.1016/j.apgeog. 2010.04.006.

Salvati, L., Kosmas, C., Kairis, O., Karavitis, C., Acikalin, S., Belgacem, A., Solé-Benet, A., Chaker, M., Fassouli, V., Gokceoglu, C., Gungor, H., Hessel, R., Khatteli, H., Kounalaki, A., Laouina, A., Ocakoglu, F., Ouessar, M., Ritsema, C., Sghaier, M., Sonmez, H., Taamallah, H., Tezcan, L., de Vente, J., Kelly, C., Colantoni, A., Carlucci, M., 2016. Assessing the effectiveness of sustainable land management policies for combating desertification: a data mining approach. J. Environ. Manage. 183, 754-762. https://doi.org/10.1016/j.jenvman.2016.09.017.

Salvati, L., Kosmas, C., Kairis, O., Karavitis, C., Acikalin, S., Belgacem, A., Solé-Benet, A., Chaker, M., Fassouli, V., Gokceoglu, C., Gungor, H., Hessel, R., Khatteli, H., Kounalaki, A., Laouina, A., Ocakoglu, F., Ouessar, M., Ritsema, C., Sghaier, M., Sonmez, H., Taamallah, H., Tezcan, L., de Vente, J., 2015. Unveiling soil degradation and desertification risk in the Mediterranean basin: a data mining analysis of the relationships between biophysical and socioeconomic factors in agro-forest landscapes. J. Environ. Plann. Manage. 58, 1789-1803. https://doi.org/10.1080/ 09640568.2014.958609.

Salvati, L., Zitti, M., Ceccarelli, T., 2007. Integrating economic and environmental indicators in the assessment of desertification risk: a case study. Appl. Ecol. Environ. Res. 6, 129-138 https://doi.org/10.15666/aeer/0601_129138.

Schwilch, G., Hessel, R., Verzandvoort, S.J.E. (Eds.), 2012. Desire for Greener Land: Options for Sustainable Land Management in Drylands. University of Bern, Centre for Development and Environment CDE; Alterra, Wageningen UR; ISRIC - World Soil Information and CTA - Technical Centre for Agricultural and Rural Cooperation, Bern, Switzerland, and Wageningen.

Skondras, N.A., Karavitis, C.A., Gkotsis, I.I., Scott, P.J.B., Kaly, U.L., Alexandris, S.G., 2011. Application and assessment of the Environmental Vulnerability Index in Greece. Ecol. Ind. 11, 1699-1706. https://doi.org/10.1016/j.ecolind.2011.04.010.

Steel, R.G.D., Torrie, J.H., Dickey, D.A., 1996. Principles and procedures of statistics: a biometrical approach. Subsequent Edition. McGraw-Hill College, New York.

Thomas, D., 1997. Desertification: the uneasy interface between science, people \& environmental issues in Africa. Rev. Afr. Polit. Econ. 24, 583-589.

Tsakiris, G., Vangelis, H., 2004. Towards a drought watch system based on spatial SPI. Water Resour. Manage. 18, 1-12. https://doi.org/10.1023/B:WARM.0000015410. 47014.a4.

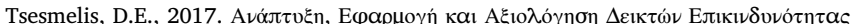

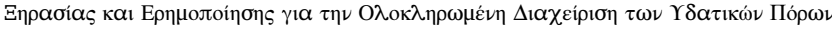
(Development, implementation and evaluation of drought and desertification risk indicators for the integrated management of water resources) (Ph.D. Dissertation). Department of Natural Resources Development and Agricultural Engineering, Agricultural University of Athens, Athens, Greece (in Greek).

Tsesmelis, D.E., Karavitis, C.A., Oikonomou, P.D., Alexandris, S., Kosmas, C., 2019a. Assessment of the vulnerability to drought and desertification characteristics using the standardized drought vulnerability index (SDVI) and the environmentally sensitive areas index (ESAI). Resources 8, 6. https://doi.org/10.3390/resources8010006.

Tsesmelis, D.E., Oikonomou, P.D., Vasilakou, C.G., Fassouli, V., Skondras, N.A., Alexandris, S., Grigg, N.S., Karavitis, C.A., 2019b. Assessing structural uncertainty caused by different weighting methods on the standardized drought vulnerability index (SDVI). Stoch. Env. Res. Risk Assess. https://doi.org/10.1007/s00477-01901648-4.

UNEP (Ed.), 1992. World Atlas of Desertification. Edward Arnold, London; Baltimore. van Engelen, V., Wen, T., 1993. Global and national soils and terrain digital databases (SOTER): procedures manual, World soil resources reports. Land and Water 
Development Division, Food and Agriculture Organization of the United Nations, Rome.

van Engelen, V.W.P., Wen, T.T., 1995. Global and National Soils and Terrain Digital Databases (SOTER): Procedures Manual, (Published also as FAO World Soil Resources Report No. 74). UNEP, IUSS, ISRIC, FAO, Wageningen, pp. 115.

van Engelen, V.W.P., Batjes, N.H., Dijkshoorn, J.A., Huting, J.R.M., 2005. Harmonized Global Soil Resources Database (No. Report 2005/06). ISRIC - World Soil Information and Food and Agriculture Organization of the United Nations, Wageningen.

Vlachos, E.C., 1982. Drought Management Interfaces. Annual American Society of Civil Engineers Conference, Las Vegas, Nevada, USA, p. 15.

Wascher, D.M. (Ed.), 2000. Agri-environmental indicators for sustainable agriculture in
Europe, ECNC publication technical report series. European Centre for Nature Conservation, Tilburg.

Witlox, F., 2005. Expert systems in land-use planning: an overview. Expert Syst. Appl. 29, 437-445. https://doi.org/10.1016/j.eswa.2005.04.041.

WOCAT, LADA, DESIRE, 2008. A Questionnaire for Mapping Land Degradation and Sustainable Land Management. Centre for Development and Environment, Institute of Geography, University of Berne, Berne.

Wu, H., Svoboda, M.D., Hayes, M.J., Wilhite, D.A., Wen, F., 2007. Appropriate application of the standardized precipitation index in arid locations and dry seasons. Int. J. Climatol. 27, 65-79. https://doi.org/10.1002/joc.1371.

Yevjevich, V., da Cunha, L., Vlachos, E., 1983. Coping with droughts. Water Resources Publications, Littleton, Colorado. 